\title{
ARTISTRY AND ANALYSIS: STUDENT EXPERIENCES OF UK PRACTICE-BASED DOCTORATES IN ART AND DESIGN
}

\section{Jacquelyn Allen Collinson}

June 2003

University of Gloucestershire Leisure \& Sport Research Unit Oxstalls Campus Gloucester 


\section{GL2 9HW}

Tel: 01452876664

Email: jcollinson@glos.ac.uk 


\title{
ARTISTRY AND ANALYSIS: STUDENT EXPERIENCES OF UK PRACTICE-BASED DOCTORATES IN ART AND DESIGN
}

\begin{abstract}
During the last decade, doctoral education has been the focus of much international academic attention. This period has also witnessed the rapid growth of practice-based research degrees in art and design in the UK. To-date, however, there has been no extensive empirical research on the subjective experiences of students undertaking this form of doctorate in art and design. This paper, based upon qualitative interviews with 50 UK students at 25 different institutions, seeks to examine from a sociological perspective the occupational life-worlds of these students, and the risks they take in choosing to study for a doctorate. It explores some of the narratives which students generated during their often faltering and difficult transformational journey from 'creator' to 'creator-researcher' during the process of the research degree, focusing in particular upon the perceived tensions and contradictions between their artistry and analysis.
\end{abstract}




\section{Biographical Note}

Jacquelyn Allen Collinson is a Research Fellow within the Leisure \& Sport Research Unit, and a Research Associate with the Faculty of Education \& Social Sciences at the University of Gloucestershire. Her principal research interests include: occupational and sporting identities, socialization processes, and research degree education. Projects currently underway include a qualitative study of the life-worlds of practice-based research students and their supervisors in art and design.

Correspondence to Jacquelyn Allen Collinson, University of Gloucestershire, Leisure \& Sport Research Unit, Oxstalls Campus, Gloucester, GL2 9HW, UK. Email: jcollinson@glos.ac.uk 


\section{ARTISTRY AND ANALYSIS: STUDENT EXPERIENCES OF UK PRACTICE-BASED DOCTORATES IN ART AND DESIGN}

\section{Introduction}

During the last decade in particular, research degree education has been the focus of much international academic attention (cf. Royal Society of Canada, 1991; De Wied, 1991; Bowen \& Rudenstine, 1992; Zuber-Skerritt \& Ryan, 1994), and a UK-specific literature has also proliferated (Burgess, 1996). This period has also witnessed the rapid growth of practice-based research degrees in art and design in the UK (Painter, 1996; Candlin, 2000). Although there has undoubtedly been an advance in knowledge about doctoral students in the disciplines falling within the natural sciences, social sciences and humanities (Burgess, 1994; Delamont et al, 1997; Graves \& Varma, 1997), this does not hold for empirical studies of students undertaking practice-based research degrees in art and design. This route to the PhD still constitutes an innovative, and on occasion a disputed form of UK research study (cf. Macleod, 2000), which emerged primarily out of the old Council for National Academic Awards' framework (CNAA, 1989) which regulated the former polytechnics until 1992. The requirements which distinguish this research degree from the more 'traditional', purely written forms can be summarised as follows:

- the final submission must be accompanied by a permanent record of the creative work(s);

- the creative work must be set in its relevant theoretical, historical, critical or visual context;

- the length of the accompanying written thesis must normally be between 30,000 and 40,000 words;

- the written thesis and the creative work must be of equal or near equal importance (UKCGE, 1997: 15) 
Normally, the student's work must also conform to the more traditional aspects of UK research degree regulation, in terms of originality, independence, and the undergoing of a viva voce examination. This kind of doctoral study presents students with an interesting challenge in combining elements of their creative work (painting, design, photography, ceramics, printmaking and so on) with a written analysis of that work in text, CD or other form. Presently, there is little empirical knowledge of how students handle and achieve this combination (cf. Macleod, 1998), and how they seek to resolve some of the tensions and contradictions between the artistic and analytic dimensions of their work. This paper therefore aims to address this lacuna by setting out the findings of some exploratory, qualitative sociological research.

\section{The research}

The research was based upon single, qualitative interviews with 50 research students (27 male; 23 female), located at 25 UK universities and colleges and undertaken by a team of two researchers, both with disciplinary backgrounds in sociology. It had originally been planned to undertake follow-up interviews to chart the progress of the students, but unfortunately financial constraints precluded this. It should also be noted that the research was not designed to generate detailed individual student case studies. The limitations of the 'single research technology' (Berg, 1989: 4), the 'snapshot', single-interview approach should therefore be borne in mind. In defence of the interview method, however, it has been emphasized that: 'Accounts are all we have to work with' (Gilbert \& Abell, 1983: 2-3), and the students' accounts constitute the focus of the research.

Interviews were in-depth, semi structured, and tape-recorded, of between 60 and 90 minutes' duration. Interviewees spanned the spectrum of art and design subjects, including painting, ceramics, installation, photography, printmaking, sculpture, glassmaking and design. Students also fell on a continuum ranging from individuals in their first year of study to those near the 
point of submission. Twenty of the students were studying part-time, many of whom had considerable experience of earning a living via their creative endeavour.

The primary purpose of the interviews was to gain an understanding of students' lived experience. The interview agenda covered topics such as relationships with research supervisors, relationships between practice (making) and theory, practice and artistic community, practice and the self, practice and writing, and students' conceptions of identity. Students were also encouraged to talk about any other issues of significance to them. Given the relative paucity of research on these practice-based students, the aim of the project was not to provide statistical generalizations, but to seek to uncover something of the complexity of students' academic lives at various points on the pathway to doctoral status. In common with much qualitative research, therefore, extrapolation from the data relies on the validity of the analysis rather than the representativeness of the events' (Mitchell, 1983). Data analysis was carried out via a process somewhat akin to the constant comparative method (Glaser, 1993), in that data collection and analysis were synchronous and ongoing, but in a less formalized fashion. Subsequently, detailed manual coding allowed the generation of key thematic categories and subcategories of the students' experience. This process of analysis continued until no new categories, in terms of social processes, practices and conceptions, were emerging from the data (Creswell, 1998).

As Jenkins (1996: 29) notes, the concepts of 'self' and 'identity' can be argued to be coterminous, with self as 'each individual's reflexive sense of her or his own particular identity, constituted vis à vis of others in terms of similarity and difference'. This internal understanding of a fully reflexive self is a product of the social interaction out of which it emerges (Mead, 1934). In particular, the paper focusses upon the self which students construct, maintain, and modify whilst in the role of creator/maker, and eventually, researcher. The paper aims to portray 
some of the processes of identity construction and modification via an analysis of the various student stories or narratives which were articulated during the interviews.

The importance of narrative activity has been emphasized by many, including those who contend that narrative and identity are in fact inseparable in that narrative is born out of experience and simultaneously gives shape to experience (Ochs \& Capps, 1996). The method of narrative analysis focuses on the ways in which people organize and assign meaning to their experience, and seeks to explore how particular identities are constructed via that experience; as Anderson and Williams (2001: 4) succinctly phrase it: 'Narratives are the bricks with which we construct our identities...' Narratives also combine the social with the personal (Coffey \& Atkinson, 1996), for, as Sparkes (1999) has noted, personal stories are intimately linked to the cultural and subcultural resources upon which actors can draw.

The analysis of the interview data reveals a complex interweaving of narrative resources as students portrayed their progress from the status of research novices to the point of thesis submission. As students gradually acquired research experience and expertise, they described how their identity evolved, and comparison of the interview transcripts generated a rich mosaic (Becker, 1977) of their experience. As noted above, it was unfortunately not possible to undertake longitudinal research, and therefore to chart individual and group change over a certain time span. Elements of the data from all stages of the student experience, however, have been utilised to create a composite picture portraying the changes which students described in some detail as occurring during their doctoral study. In order to convey the processual nature of identity transformation, the data have been presented in chronological fashion. In this way the emergence of the narrative(s) parallels the temporal framework of the process of identity change. However, the limitations of this essentially linear presentation of the data should be noted. As Hammersley and Atkinson (1983: 220) have emphasized, this form of portrayal implicitly suggests 'a more or less smooth set of transitions from one stage to 
another'. The reality of student experience is, of course, more complex and fragmentary. For example, in the text are presented narratives of trouble and struggle, which are subsequently supplanted by narratives which describe new kinds of learning and skill. Whilst troubles may indeed be surmounted, this is never in a 'once and for all' sense, but requires repeated efforts as problems and tensions inevitably recur. It should consequently be kept in mind that student identity change is both a practical and continuous accomplishment (Benson \& Hughes, 1983), with elements of circularity in addition to the linearity which structures this particular paper.

The creative self and its tensions

Upon commencing their doctoral study, students already possess a set of practical dispositions (action), perceptions and motivations, grounded in their particular creative activity, which they use as a resource to solve creative problems. This form of essentially embodied resource has been conceptualised by Bourdieu (1990: 55) as habitus; in this instance situated within the general field of art and design. Problem-solving entails what Bourdieu has termed: 'a feel for the game', which allows the individual to adopt the right strategies and make the correct decisions in the act of making. When they commence the doctoral programme, however, students must also develop a feel for the game of research, which is situated within the field of higher education (Bourdieu, 1988). It is the construction of this synthesized form of habitus, of both creator and researcher, which generates certain tensions and contradictions which will constitute the focus of discussion later in the paper.

The interviews clearly revealed that when commencing their research study, all students held primarily to a sense of the creative self which was of paramount importance to them. This was articulated via self-categorizations such as: artist, photographer, ceramicist, designer and so on. When probed as to the essence of this, 'creativity' and being a 'creative person' were deemed central to their sense of identity, or in Stryker's (1987) terminology, to have 'identity salience'. The interviews subsequently sought to uncover some of the specific components of that self-defined creativity, and various themes depicting particular qualities and characteristics 
emerged from the data. These elements were found to be present regardless of medium used (print, paint, glass, metal, film, and so on). They are not presented in any order of priority but rather as the elements comprising a rich amalgam which underpins creative endeavour.

Of marked importance to the students interviewed was the high value placed upon a strong emotional presence within their making. Their capacity to respond emotionally to materials was felt to be vital to the creative processes and to the construction of objects of originality. The deployment of a repository of feelings (cf. Denzin 1984: 1-3) was viewed as crucial for their creativity, as these feelings were expressed both within and through their work. Intimately connected to this emotional wellspring was the element of intuition. Students perceived themselves as intuitive individuals whose creativity was heavily dependent upon a capacity "to feel when things are right", as one phrased it. The use of intuition applied to processes as diverse as, for example, the mixing of colours, the application of temperatures to materials, or the juxtaposition of objects. Intuition was also linked to notions of spontaneity and responsiveness to impulses emanating from the creative imagination. A further quality interviewees perceived in themselves was that of openness, in terms of receptivity to new ideas, and willingness to explore in innovative directions. Ultimately, all these qualities and characteristics were perceived to be highly influential in facilitating their creative work.

Holding these conceptions of identity, students then encounter with some shock the new domain of research, where supervisors, research training courses, and methodology texts, for example, place great emphasis on somewhat different values. In essence, research was presented to students as a highly rational process, which involved the erection of abstract categories so as to formulate theory. 'Objectivity' in the form of analysis, the precise formulation of argument, the logical progression of ideas and the systematic collection of evidence, was also heralded as a necessary component of effective doctoral research. New parameters of correct conduct and procedure provided powerful messages to students. In 
addition, students' research projects are subject to a framework of institutional regulations which impose additional demands upon doctoral candidates, for example in terms of timescales and prescribed formal structures. Projects must be approved by committees responsible for 'quality assurance'. This combination of research-related and bureaucratic demands, was usually at considerable variance with the way in which students had previously conducted their creative making, and also, importantly, with their conceptions of the creative self. This is not to say, of course, that students were not already familiar with the discipline and rigour of the creative process, but rather than the new requirements of doctoral research placed different, academic demands. Tensions were consequently evident at the level of identity, and some of the means by which students resolved these will now be examined.

\section{Narratives of confusion and constraint}

Initially, when encountering these contrasting and countervailing imperatives, students felt confused. Generally, their prior experience of art and design education had contained little to forewarn and prepare them for the specific strictures of doing doctoral research, nor the regulatory framework within which they were required to operate. This is usually in some contrast to the natural and social sciences where exposure to the discipline-specific protocols of research normally occurs at a relatively early stage of undergradute study. In comparison, of the cohort interviewed, only a handful indicated any knowledge of formal research methods and canons, and this had been via art history courses, or design ergonomics. Although a majority of interviewees had actually studied at Master's level, these degrees were predominantly based solely on the submission of individual creative output, without any formal research component. Whilst all students had some prior experience of academic forms of writing, the volume and sophistication demanded at research degree level were perceived as unsettling and intimidating. The process of drafting a research proposal, specifying temporal plans, the particular linguistic forms in which such plans have to be codified, and all the associated bureaucratic process (applications forms, vetting committees, approval processes), 
all had highly negative connotations for students. Distress and confusion were consistent narrative themes at this point in their research careers. For example, one lamented:

“How can I do what they (supervisors) want me to do, and do my art? I don't understand how I can do it all! It has really unsettled me and I can't see how I can go forward with it all...I suppose l've always felt myself to be an expressive person, and the ways of doing research seems the opposite. I don't want to feel like that, so where do I go from here?"

This kind of narrative was reinforced by others, as students initially perceived the combination of bureaucracy and research protocols as fundamentally detrimental to their creative activity and consequently to their creative selves. As Bourdieu (1984: 3) and others (Berg, 1983: 1656; Griff, 1960: 223) have noted, people in the creative arts place great emphasis on their autonomy and control over the making. From the students' perspective, these heavy constraints impinged upon their creative selves, and consequently narratives of constraint were salient. The intuitive, emotional, spontaneous and 'open' self was confronted by institutional processes, and academic demands, which seemed intent on limiting, managing and packaging creativity into tight timescales and pre-defined forms. These constraints produce boundaries which in a sense are the antithesis of the creative freedom previously experienced. For those interviewed there was a particular irony evident in this situation, for they were embarking on potentially the most exciting and extensive exploration of their creative impulses, whilst simultaneously those very impulses were subject to restriction by forces not previously imagined.

"As soon as I start putting down structures, I can't write freely, so it becomes disjointed and difficult. Writing academically is not free; it's very structured, with very tight boundaries for a thesis. It generally leaves me angry which is propably why it's difficult to write...It's just the institution that makes the rules that tie people, and in contrast art 
practice is about enabling people to freely express themselves and subvert boundaries. So here I am struggling with those academic boundaries that I find quite restrictive, so I've had terrible conflicts about that."

The interviews indicated that ambivalence towards these constraints was felt by students for long periods of time during the research degree process, and any shift in perception manifested itself only when certain changes at the level of identity had occurred. These changes will be depicted later in the paper. 


\section{Narratives of sacrifice and risk}

The vocabulary of motives (Mills, 1940), which had propelled students into research, valorized the need to develop and extend their creative practice to new levels. For some the acquisition of an advanced qualification was also valued as a potential route to an academic post, which would then provide institutional funding for their own practice (cf. Finney, 1997: 78-79). In trying to come to terms with the new reality and the unfamiliar constraints, students perhaps inevitably began to question their motives. What they could gain or achieve was contrasted with what they might risk losing or sacrificing. On the economic level, students bemoaned the monetary sacrifices involved in remaining full-time students or paying their own fees as part-time students. This was often accompanied by statements stressing that generally very few artists and designers receive reasonable long-term financial reward for their creative output (cf. Mishler, 1999: 130 ). It was therefore questionable whether the time and energy expended on the uncertain path towards the doctorate was worth the sacrifice. On another level, all those interviewed initially viewed as a compromise the accommodations they were obliged to make to the structuring of their research in response to bureaucratic and research demands. They felt strongly that this had the potential to reduce the power of their aesthetic output, and this could have negative consequences for their future reputation within the community of creative peers, both inside and outside academia. This potential sacrifice was viewed with considerable alarm; in the words of one:

"I do not want to end up with a title before my name and people at my doctoral show ruminating over the fact that it took me years to produce such mediocre work!"

In addition, the time and energy devoted to the research component of their work, such as comprehensive literature reviews, systematic documentation, historical positioning, formal analysis of practice, theorising and so on, was also viewed with a jaundiced eye. The more time and energy devoted to this component, the less was available for their actual practice. 
There was consequently a tension between these activities, for no matter how intimately connected to the making, the research components were no substitute for the making per se. Hence, time spent away from their practice was construed as a sacrifice demanded by the doctoral process, and one which might produce no positive return in the long term. The enforced decrease in effort for the making would, they feared, result in reduced creative output and less momentum in producing original works.

"The physical act of analysing and writing like that and the kind of thought that goes with it, it takes time and it's a different kind of time and a different kind of being than when you are making... Part of you is feeling that you should be in another place, in the studio making something, which feels more real, so you miss it. And you feel uneasy because being away from it you feel it is suffering... I mean the quality of it, how much progress you are making."

From the student standpoint these sacrifices were of considerable significance, given the feared negative consequences for both their creative making and artistic reputation.

Rooted in scenarios which involved the taking of such chances, students also articulated narratives of risk. These narratives were somewhat more specific than those relating to sacrifice, being directly connected to particular problems which had already arisen or they feared would arise. A highly problematic requirement for students was the need to portray analytically the process of their making, and to situate it within broader academic contexts of history, theory, biography etc. This required the systematic accumulation, and eventual presentation, of evidence and explanation, placing their own creative processes and subjectivity under the microscope of dispassionate analysis. For students, such analytical documentation involved a high degree of self-disclosure. Regardless of whether their research was geared to audience impact (eg fine art) or aimed at uncovering the process of making 
(ceramics, glass etc), a good deal of anxiety was manifest amongst students at the threat posed by this dénouement. The risk was articulated in a number of ways. Great unease was expressed at the thought of routines of creativity being laid bare. Although students were familiar with audience judgment of their finished creative work, public scrutiny of the creative process per se was unfamiliar and threatening. It was feared that the processes of production would be judged not as innovative but as merely mundane and routine, and that this judgment would have deleterious consequences for the way in which the final creative product was perceived. These concerns related not just to the judgment of an academic audience, but also of the wider creative community. As one student indicated:

"I find it quite disturbing that I'm supposed to reveal all the inner workings of what I make... Well, one likes to think one has individual ways of doing things, of putting things together, of choosing things, that sort of stuff.. Up to this point all that has been a private affair, and I suppose I have felt them to be special... Well, in the sense that they are mine, and they have some quality to them. The problem with this revealing is that in a way I feel they might then no longer be mine, and they might be viewed as having no quality at all!"

Students also emphasized the risk of more personal disclosure. In seeking an 'objective' and detailed understanding of how their practice worked, they feared that such knowledge would impinge upon their emotional capacity to create and innovate. Gains in terms of the development of analytical thinking were perceived to threaten their very creativity; the prized qualities of intuition, openness, and spontaneity might be constrained, distorted, desiccated, by this new found power. Students feared that the more time expended on the analysis, the greater the risk to creativity. Transition between the modes of creativity and analysis required of them not just different ways of thinking (described as 'subjective'/'objective') but, more fundamentally, differences in feelings, actions, and being: 
"To do the analysis you have to be apart from it and to do it (the making), well it's part of you. The problem is that moving away from myself (analysis) is still alien. When I go back (to making) it's very difficult to be just with the clay because the distance keeps on coming in again... What I mean is all the questioning about why I am doing it and how I am doing it, so it means I have to struggle to be with the material, and before I just did it automatically".

At the level of identity, this shifting between different modes of thinking, feeling and ultimately doing, was perceived to create ambiguity and tension. In the domain of analysis, students are inevitably inexpert at this stage of their academic development, and consequently not confident in their ability. Worse still, their attempts at analysis have the capacity to disrupt their creative energies and expertise, making credible conceptions of identity difficult to sustain in both domains. Upon encountering the new terrain of doctoral study, students initially attempted to make sense of their experience via narratives of confusion, constraint, sacrifice and risk. These narratives were redolent with unease, uncertainty and anxiety as students struggled to understand and make progress in their studies. The following sections will attempt to illustrate how this was achieved via a further set of narratives.

\section{Narratives of discovery}

Students enter doctoral study with considerable expertise in making, in whatever medium. When questioned about this expertise, two salient points emerged. First, there was a haptic facility (Rose, 1999) which allowed them to manipulate materials and construct objects; a capacity based on an appreciation of the qualities and limits of the materials with which they worked. This facility was both symbolically and physically located in their hands; in the words of one student: "My hands are everything to me". Second, and intimately connected to this manual dexterity and sensitivity, was a particular way of seeing (Goodwin, 1994, 1995), 
developed to a high degree of sophistication, and attuned to features such as the synthesis of colours, the relationship between objects, the configuration of different shapes, the complexities of light etc. Whilst this expertise is brought into the research arena, it alone cannot guarantee successful completion of a PhD. To achieve the latter, students need to acquire expertise in the craft practices (Mills, 1975) of research. However, as previously depicted, there exists a tension between conceptions of their emotionally-charged creative identity, and the more rationalist and objectivist canons and procedural framework integral to research craft, at least in terms of how this is presented to students

As the research journey progresses, students struggle with developing this new academic craft. On one level this requires an understanding and acceptance of research as a particular paradigm, with its philosophical foundations, requirements (usually of validity, reliability etc) and processes (data accumulation, analysis etc). Students must also engage with theoretical and conceptual thinking and its application to their making. On a less abstract level, they have to acquire the practical competencies involved for instance in doing interviews, constructing studio/workshop analytic notes on practice, searching archives, and so on. Given the salience of their creative self and the knowledge that has been imparted to them about research, the interviews revealed that their conceptions and fears of research centred upon the fact that it was perceived to be an essentially technical and/or mechanical process, with the potential to constrain and even endanger their creativity. Their struggle then was not just with the leaning of new skills and competencies, but crucially also with the development of a self-conception which would allow the accommodation of this very different set of activities. What transpired was the modification of identity in relation, and in response, to their research.

Students who managed this transformation successfully, learned to develop an affinity between their practice and their research on that practice. These students came to realise that their new research craft was itself creative, in ways which they had not previously 
understood or envisaged. More crucially, they reached a stage where they felt they were creative in the actual analysis of their practice. This constituted a process of discovery and was depicted in various narrative forms, including the development of a perspective on the research process as a creative act. This was achieved very gradually as students came to recognize similarities between what they made, and the research process itself. So, they acknowledged that their making followed a developmental cycle, from initial ideas, through selection of materials, design, construction, revision, to final production. An analogous process could be detected in the research program. Students also came to realize that this process was not in fact a purely mechanical one, but one which required considerable innovation, change and adaptation:

\footnotetext{
"When I work, I use lots of different materials and I build one shape or a series of them and what I enjoy is the challenge of getting the different materials to fit and getting the relationship between each shape and its neighbour to fit. In trying to make sense of the work and document it, I have been playing around with different theories and concepts, like synchronicity and serendipity, and I have realised it's sort of similar in terms of process. By doing that I have begun to grasp how my work actually 'works', and I can see the overall pattern of its development, so in that sense it's also a creative process... I play around with the physical materials and I play around with different kinds of, I suppose mental materials, so I can construct explanation."
}

Along with the acknowledgement of research as a creative process, another narrative of discovery was generated concerning the analytical writing. With few exceptions, those interviewed could not be considered skilled in analytical writing. Their previous education (at undergraduate and Master's levels) had placed great emphasis on communication via making, with little requirement for written communication. Students were well aware of their lack of facility in this medium and were initially very uncomfortable with written analysis, and unsure of 
its role as a medium of expression. As one put it: "I'm not self conscious about the drawing but I'm self-conscious about the writing because it's not my language."

Incrementally, via much struggle and hard work, students develop a facility in analysis in the written text in one form or another. This constitutes a vital developmental step, for without analysis, all the other activities of research cannot be fully communicated. Interestingly, students often characterized this new skill of writing in terms of a positive change in the use of their hands. Previously, the focus of their hands had been with the making, now their hands were capable of working at a sophisticated level in another dimension. Whilst individuals did not deny a cognitive aspect to their analysis, there was repeated expression of the importance of their hands in constructing the analysis. Whilst not following Barthes (1977) entirely in entrusting the hand with the task of writing as quickly as possible, and in almost automatic fashion before the head is aware of the thought, students certainly described a sense of flow in the physicality of their writing:

\footnotetext{
"Gradually it's got better and I can tell it's not just because I have got chapters written which have been approved by (supervisor). It's also because my hands no longer feel clumsy when I write, I can get a flow going, it's not disjointed like it used to be. I have a sense now of how writing in an academic fashion can be creative, whereas before I instinctively felt it was 'dead' and not my thing at all."
}

Perhaps surprisingly in an age of technological advancement, few of those interviewed created text initially on computer screen. Instead, the vast majority chose to use more traditional means (notebooks, logs, diaries, etc), and then transfer the handwritten draft to computer.

Students often compared the process of developing proficiency at analytic writing with previous experiences of being novices in art and design, or perhaps when they had changed 
one creative medium for another (drawing to design, etc). They recalled their struggle to become skilled at the new activity, and experiencing reduced powers of expression. Once again they recognized an affinity between their making and the processes of research. This then changed their previous conceptions of research as a 'deadening' activity which limited or threatened their creative selves. They began to develop a particular construction of research, they engaged in analytic, academic writing and thereby discovered that research was not beyond their abilities, and more importantly not antithetical to their practice, and its essence, their creativity. From this discovery flowed other kinds of narrative, which helped them further to identify with the role of researcher and to incorporate this into their conception of self. As Richardson (1994: 516) has noted in relation to the power of writing: "Writing is also a way of 'knowing' - a method of discovery and analysis. By writing in different ways, we discover new aspects of our topic and our relationship to it."

\section{Narratives of empowerment and transformation}

The gradual development of competence in the research craft begins to generate confidence in that craft. The result is that students found themselves intellectually and aesthetically boosted by their newly acquired and hard won research expertise, and this was expressed via various narratives of empowerment, for example, around their confidence in general research proficiency. Empowerment was also experienced in relation to the skilled use of the tools of research (theory, concepts, techniques and so) which could actually aid creative output in a number of ways. One of these narratives of empowerment centred upon the development of insight into the individual's own making, which in turn produced new ideas for innovative work:

"I have been working as an artist for ten years and l've found actually that this (PhD) has benefited the way I work. It's impacted upon how I go about the process of making work which is a valuable thing. I know I am more sort of vigorous in terms of understanding why I choose particular images of subjects, and how I interpret them in relationship to 
myself. I've found that kind of understanding has helped me move the work in certain profitable directions."

These kinds of narratives focus upon the advantages in aesthetic terms of developing a capacity to analyze individual creative method, as opposed to fearing the analytic mode. A second empowering narrative stressed the benefit of gaining a deeper appreciation of the wider creative context in which individual making was situated. An in-depth understanding of the histories of culture, theory, and of particular major innovators in an individual's area, were all felt to be valuable resources gleaned via doctoral study. Such resources allowed students fully to situate themselves and to contextualise their work within their intellectual and aesthetic pedigrees. By coming to comprehend, in great detail, how their work was constructed, its intellectual locus, why it was being propelled in certain directions, and so on, the relationship to that work changes. Students understand the totality of their work, and this comprehension generates another narrative of empowerment, relating to the capacity to articulate, to voice their work, both to themselves and to their public. So, analytic confidence, rooted in a thorough understanding of their work in terms of decisions and choices made, its precise amalgamation of elements, and its contextual or historical place, produces and sustains a more developed capacity to articulate and justify the making:

"A few years ago at shows of my work or when giving a talk about it, I was sort of a 'straw woman' ... I would talk about my work but there was always a gap in my understanding of it, and of my place in it. I was always uneasy with that state of affairs, a fear of getting caught out. Now I know my work much better, and I understand my place in it, how I am with it, where I am going with it and why. When I give talks now it is a much easier process because I understand all that, and therefore I can justify all that in public." 
In turn, this insight was felt to have enhanced students' understanding of their creative self. Students generated narratives which charted the process of developing insight into the very motives which helped propel their creativity. This particular narrative emphasized not only their satisfaction at developing new analytic tools, but also their surprise upon realising that a partial transformation of self had occurred:

"Well, when I started (the PhD) I saw myself as someone who was trying to push the boundaries of the work, and it was very much just jumping into it, that was my style. I'm still jumping in, but I now use a set of tools I didn't have before, and I like using them because I'm more focused, systematic, even precise and I feel my work has got more weight now.... I'm pretty sure I wouldn't have previously described myself as being like that, so I know l've changed in a way I had not expected."

These narratives of transformation describe the incorporation of the researcher component into the self-images students held. A process of biographical change had occurred whereby the activity of research, in all its dimensions, had been accepted as meaningful in itself. This, interviewees felt, worked to enhance their creativity. In effect, students embarked on a narrative journey which can be charted as follows (recalling that the apparent linearity is for analytic purposes only). The original narratives of confusion and constraint resulted in the production of narratives of sacrifice and risk, as creative capacity seemed to be under threat. However, whilst grappling with these threats, students uncovered a creative dimension to the research process which they portrayed via narratives of discovery. Narratives of empowerment emerged, as newly-developed analytic powers were found to enhance their making. The deeper appreciation of the totality of their work in turn produced a greater understanding of the creative self, resulting in narratives of change and identity transformation.

\section{Conclusion}


The students' transformational journey is of course social, for as Mead (1934) long ago pointed out, audience response and validation is vital for the construction, maintenance and change of individual identity. The interviews revealed that, perhaps not surprisingly, such validation was primarily sought from, and provided by fellow students, together with PhD supervisors, as students constructed, 'performed', and communicated their partially transformed selves. The students subsequently engaged in interactional practices with their audiences which helped substantiate the new self. This resulted in a 'dialectic of identification' (Jenkins, 1996: 20) with their new-found role of creator-researcher.

Upon commencing their doctoral study, students already possess a set of practical dispositions (action), perceptions and motivations. This form of essentially embodied resource, the habitus (Bourdieu, 1990: 55) is situated within the general field of art and design. Problem-solving entails what Bourdieu has termed: 'a feel for the game', which allows the individual to adopt the right strategies and make the correct decisions in the act of making. As portrayed, during the process of doctoral study, students also begin to get a feel for the game of research, which is situated within the field of higher education (Bourdieu, 1988), and in turn to solve their research problems. Students therefore construct and inhabit a form of synthesized habitus. On the one hand, this synthesis involves formally transmitted technical expertise, such as knowledge about the temperatures at which materials (glass, metal, clay etc) transform, or how to run software packages. On the other hand, it involves the assimilation of what Polanyi (1983) has termed 'tacit knowledge', for example, familiarity with the kind of shapes in to which certain materials can be sculpted; knowing when to ask a particular kind of interview question. The newly-formed habitus then provides the bedrock of practice from which students construct the identity of creator-researcher. In terms of identity salience (Stryker, 1987); it is this ordering of the role with which they identify, rather than that of researcher-creator. This is perhaps not surprising, given the relative weight of biographical time and energy devoted to the making and to the research respectively.

This paper has attempted to describe and examine the sense-making activities of students as they struggle to adapt to the unfamiliar terrain of research, and to integrate it with their creative practice. The various 
student narratives depicted above cohere to form the overarching narrative of personal change, which recounts the partial transformation of identity both to the self as audience and to other, external audiences. As Sparkes (1996) has noted, narratives are not evenly distributed within contemporary industrial society, different individuals and groups having differential access. In the case of the students interviewed, those narratives of disturbance (confusion, constraint), or enhancement (discovery) of their making, were accessible due to their membership of the occupational/educational community of artists/designers. In contrast, some of the other narratives employed, such as those of sacrifice, risk, and empowerment (Miller, 1998; Green, 1997; Seymour, 1998) proliferate within the wider culture.

In terms of identity, as Kickbusch (1988) has pointed out, taking certain risks may be essential to the construction of particular social identities. For the students studied, the risk of doing research was perceived to lie in the potential damage to their practice, and consequently to the creative self. Given the centrality of creativity to their conception of identity, this risk was a considerable one. For the majority of students, resolution of this threat was achieved by the development of new perspectives and insight into the creative possibilities within the research process itself, so that artistry and analysis were successfully combined. At this watershed in their educational career, a highly significant change in student identity occurred, as they began, slowly and often falteringly, to incorporate the role of researcher into their repertoire. This may well have ramifications for the design of research training programmes for practicebased doctoral students in art and design, and also for the training of their supervisors. Some of the problems specific to the supervision of art and design research degrees have been charted elsewhere (Hockey \& Allen Collinson, 2000). It may, for example, be beneficial for supervisors to encourage students to conceptualise research as a creative activity per se, from a very early stage in their research degree careers. The particular needs of art and design doctoral students with regard to different forms of academic writing (Hockey \& Allen Collinson, 2000), and the possibility of cooperation and collaboration (Barthes, 1987) in the writing process, might also be worthy of consideration, always within the mandatory requirement for the doctoral thesis to be independently crafted and written, of course. 


\section{Acknowledgements}

The author would like to extend grateful thanks to her co-researcher on the project, Dr John Hockey, for his helpful comments, and also to the anonymous reviewers for their suggestions for improving the paper. 


\section{References}

Anderson, P. \& Williams, J. (2001). Identity and difference in higher education: 'Outsiders within'. Aldershot: Ashgate.

Barthes, R. (1987). Translated by Heath, S. Image, music, text. London: Fontana.

Becker, H.S. (1977). Sociological work: Method and substance. New Brunswick, N.J.: Transaction Books.

Benson, D. \& Hughes, J.A. (1983). The Perspective of Ethnomethodology. Harlow: Longman.

Berg, B. L. (1989). Qualitative research methods. London: Allyn \& Bacon.

Berg, M. (1983). On work, art and women: a discussion of the ambiguous position of women artists. In A. Leira (Ed.), Work and womanhood, Norwegian Studies, Report 8 (pp. 159-173). Oslo: Institute for Social Research.

Bourdieu, P. (1984). Distinction: A social critique of the judgement of taste. Cambridge: Cambridge University Press.

Bourdieu, P. (1988). Homo Academicus. Cambridge: Polity. 
Bourdieu, P. (1990). The Logic of Practice. Cambridge: Polity.

Bowen, W. G. \& Rudenstine, N. L. (1992). In pursuit of the PhD. Princetown, NJ: Princetown University Press.

Burgess, R.G. (Ed.) (1994). Postgraduate education and training in the social sciences: Processes and products. Jessica Kingsley: London.

Burgess, R.G. (1996). Trends and developments in postgraduate education and training in the UK. Journal of Education Policy, 1 (1), 125-132.

Candlin, F. (2000). Practice-based doctorates and questions of academic legitimacy. International Journal of Art \& Design Education, 19 (1), 96-101.

Coffey, A. \& Atkinson, P. (1996). Making sense of qualitative data. London: Sage.

Council for National Academic Awards (CNAA) (1989). Research and related Activities in Art and Design, CNAA: London.

Creswell, J.W. (1998). Qualitative inquiry and research design. London: Sage.

Delamont, S., Atkinson, P. \& Parry, O. (1997). Critical mass and doctoral research: reflections on the Harris Report. Studies in Higher Education, 22 (3), 319-331. 
Denzin, N. (1984). On understanding emotions. San Francisco: Jossey-Bass.

De Wied, D. (1991). Postgraduate research training today: emerging structures for a changing Europe. The Hague: Netherlands Ministry of Education and Science.

Finney, H. C. (1997). Art production and artists' careers: the transition from "outside" to "inside". In V. Zolberg \& J. Maya (Eds), Outsider Art: contested boundaries in contemporary culture (pp. 73-84). Cambridge: Cambridge University Press.

Gilbert, G. N. \& Abell, P. (1983). Accounts and action. Aldershot: Gower.

Glaser, B. (1993). Basics of grounded theory analysis. Mill Valley, CA: Sociology Press.

Goodwin, C. (1994). Professional vision. American Anthropologist, 96 (3), 606-633.

Goodwin, C. (1995). Seeing in depth. Social Studies in Science, 25 (2), 237-274.

Graves, N. \& Varma, V. (Eds) (1997). Working for a doctorate: A guide for the humanities and social sciences. Routledge: London.

Green, J. (1997). Risk and misfortune: the social construction of accidents. London: UCL Press. 
Griff, M. (1960). The commercial artist: A study in changing and consistent identities. In M. R. Stein, A. J. Vidich \& D. M. White (Eds), Identity and anxiety (pp. 219-241). Glencoe, III: Free Press.

Hammersley, M. \& Atkinson, P. (1983). Ethnography: Principles and practice. London: Tavistock.

Hockey, J. \& Allen Collinson, J. (2000). The supervision of practice-based research degrees in art and design. International Journal of Art \& Design Education, 19 (3), 345-355.

Jenkins, R. (1996). Social identity. London: Routledge.

Kickbusch, I. (1988). New perspectives for research in health behaviour. In R. Anderson (Ed.), Health behaviour research and health promotion (pp.237-243). Oxford: Oxford University Press.

Macleod, K. (1998). Research in fine art: theory, judgment and discourse. Drawing Fire, 2 (2), 33-37.

Macleod, K. (2000). Who would falsify an art practice? Research degrees in fine art. Broadside, 5, 1-24.

Mead, G. H. (1934). Mind, self and society. Chicago: Chicago University Press. 
Miller, D. (1998). A theory of shopping. Cambridge: Polity Press.

Mills, C.W. (1940). Situated actions and vocabularies of motive. American Sociological Review, $5,904-913$.

Mills, C.W. (1975). The sociological imagination. Harmondsworth: Penguin.

Mishler, E.G. (1999). Storylines: Craftartists' narratives of identity. Cambridge, Mass: Harvard University Press.

Mitchell, J.C. (1983). Case and situation analysis. Sociological Review, 31, 187-211.

Ochs, E. \& Capps, L. (1996). Narrating the self. Annual Review of Anthropology, 25, 19-43.

Painter, C. (1996). Research degree regulations and the recognition of art and design practice: A survey report. POINT: Art \& Design Research Journal, 3 (Spring/Summer), 2-6.

Polanyi, M. (1983). Personal knowledge. London: Routledge.

Richardson, L (1994). Writing a method of inquiry. In N. Denzin \& Y. Lincoln, (Eds), Handbook of qualitative research (pp. 516-529). London: Sage. 
Rose, M. (1999). "Our hands will know": The development of tactile diagnostic skill - teaching, learning, and situated cognition in a physical therapy program. Anthropology \& Education, 30 (2), 133-160.

Royal Society of Canada (1991). Realizing the potential: a strategy for university research in Canada. Ottowa: Royal Society of Canada.

Seymour, W. (1998). Remaking the body: rehabilitation and change. London: Routledge.

Sparkes, A. C. (1996). The fatal flaw: A narrative of the fragile body-self. Qualitative Inquiry, 2 (4), 463-494.

Sparkes, A. C. (1999). Exploring body narratives. Sport, Education and Society, 4 (1), 17-30.

Stryker, S. (1987). Identity theory: Developments and extensions, in: K. Yardley, \& T. Honess, T. (Eds), Self and identity: Psychosocial perspectives (pp 89-103). New York: John Wiley. United Kingdom Council for Graduate Education (UKCGE) (1997). Practice-based doctorates in the creative and performing arts and design. Coventry: UKCGE.

Zuber-Skerritt, O. \& Ryan, Y. (Eds). (1994). Quality in postgraduate education. London: Kogan Page. 